\title{
Transesophageal Echocardiographic Identification of Anomalous Course of the Left Atrial Appendage
}

\author{
Subhrashis G Niyogi ${ }^{1}$, Krishna P Gourav ${ }^{2}$, Mandeep Kumar ${ }^{3}$, Alok Kumar ${ }^{4}$, Anand K Mishra ${ }^{5}$, Rajarajan Ganesan ${ }^{6}$
}

\begin{abstract}
The left atrial appendage (LAA) considerably varies in morphology and position. In rare cases, it can be juxtaposed on the right side. Here, we present the transesophageal echocardiography (TEE) images and surgical findings of two patients presenting for corrective surgery of their underlying congenital cardiac anomalies. While abnormal position of the LAA was detected in the first patient, juxtaposition of LAA was detected in second patient by TEE and confirmed intraoperatively.

Keywords: Juxtaposition, Left atrial appendage, Transesophageal echocardiography.

Journal of Perioperative Echocardiography (2019): 10.5005/jp-journals-10034-1096
\end{abstract}

\section{INTRODUCTION}

The left atrial appendage (LAA) is a blind-ended pouch arising from the left atrium and extending between the anterior and lateral walls of the left atrium. While typically described as narrow and finger like, it can have considerable variations in shape, tip direction, and anatomical relationship with other structures. ${ }^{1,2}$ On transesophageal echocardiography (TEE), it is visualized in the midesophageal two chamber view. ${ }^{3}$

\section{Case Description}

\section{Case 1: Abnormally Positioned LAA}

A 4-year-old male child presented with preoperative complaints of cyanosis noticed since 2 months after birth and intermittent cyanotic spells. Clinical examination showed central cyanosis, clubbing, ejection systolic murmur in the pulmonary region, and a right parasternal heave. Echocardiography and cardiac catheterization allowed a diagnosis of situs solitus, levocardia, normally related great vessels, $12-\mathrm{mm}$ subaortic ventricular septal defect (VSD) with right to left shunt, severe pulmonary stenosis, adequate sized pulmonary arteries, left sided aortic arch, and no major aortopulmonary collateral arteries. The child was hence posted for intracardiac repair of cyanotic congenital heart disease under cardiopulmonary bypass.

After induction of anesthesia, TEE examination confirmed the preoperative echocardiography findings. During TEE imaging in the midesophageal ascending aorta short axis view for evaluation of branch pulmonary arteries' size, a mobile echogenic structure was visualized posterior to the ascending aorta in the short axis view (Fig. 1 and Video 1). The absence of structural continuity with the right pulmonary artery in grey-scale imaging and absence of blood flow around the structure with color Doppler imaging virtually ruled out right pulmonary artery thrombus (Fig. 2 and Video 2). Rotating the omniplane angle by $90^{\circ}$ revealed the mobile structure to be distinct from the right pulmonary artery (Fig. 3 and Video 3). This structure was located between the right pulmonary artery, left atrium, and the ascending aorta. The finding was communicated to the surgeons who confirmed the presence of LAA in the transverse sinus (Fig. 4 and Video 4).

\begin{abstract}
1-3,6 Department of Anesthesia and Intensive Care, Postgraduate Institute of Medical Education and Research, Chandigarh, India

${ }^{4}$ Department of Anesthesia and Critical Care, Army Hospital (Research and Referral), New Delhi, India

${ }^{5}$ Department of Cardiovascular and Thoracic Surgery, Postgraduate Institute of Medical Education and Research, Chandigarh, India

Corresponding Author: Rajarajan Ganesan, Department of Anesthesia and Intensive Care, Postgraduate Institute of Medical Education and Research, Chandigarh, India, Phone: +91 9815930510, e-mail: raja2n@ gmail.com
\end{abstract}

How to cite this article: Niyogi SG, Gourav KP, Kumar M, et al. Transesophageal Echocardiographic Identification of Anomalous Course of the Left Atrial Appendage. J Perioper Echocardiogr 2019;7(1):18-21.

Source of support: Nil

Conflict of interest: None

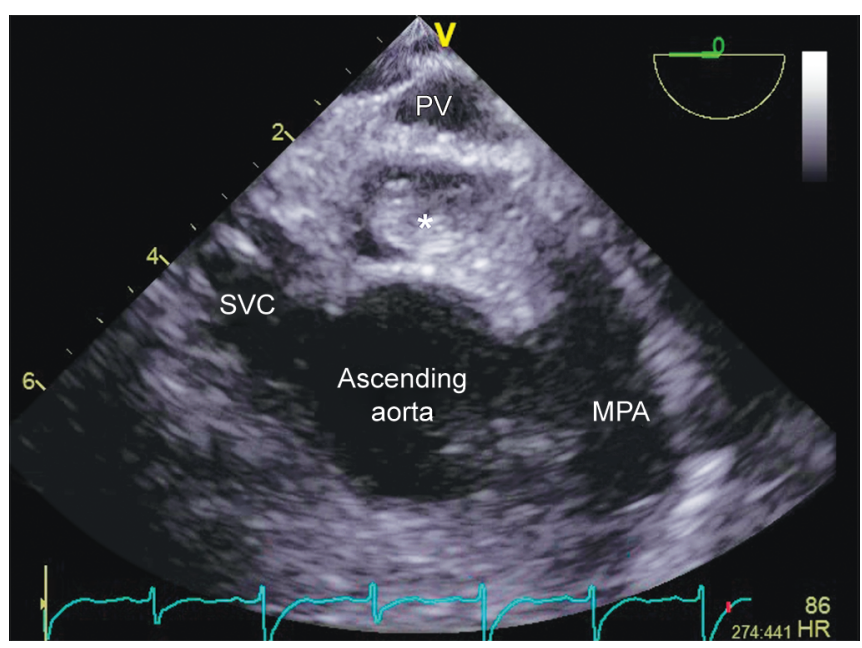

Fig. 1: Midesophageal ascending aorta short axis view in the first index case showing the left atrial appendage, marked by an asterisk $(*)$, posterior to the ascending aorta. MPA, main pulmonary artery; PV, pulmonary vein; SVC, superior vena cava

(-) The Author(s). 2019 Open Access This article is distributed under the terms of the Creative Commons Attribution 4.0 International License (https://creativecommons. org/licenses/by-nc/4.0/), which permits unrestricted use, distribution, and non-commercial reproduction in any medium, provided you give appropriate credit to the original author(s) and the source, provide a link to the Creative Commons license, and indicate if changes were made. The Creative Commons Public Domain Dedication waiver (http://creativecommons.org/publicdomain/zero/1.0/) applies to the data made available in this article, unless otherwise stated. 


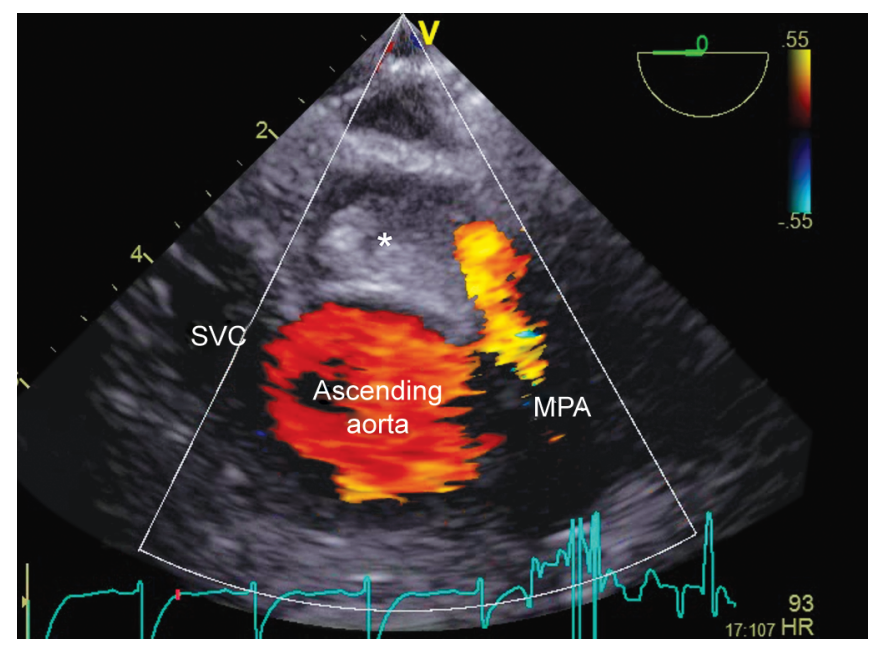

Fig. 2: Color Doppler in the midesophageal ascending aorta short axis view in the first index case demonstrating the absence of flow around the echogenic structure, the left atrial appendage $(*)$. MPA, main pulmonary artery; SVC, superior vena cava

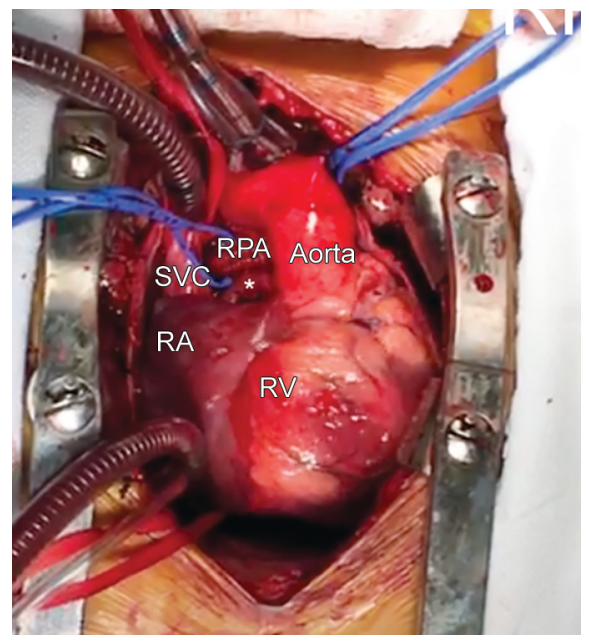

Fig. 4: Intraoperative photograph in the first index case revealing the left atrial appendage, marked by an asterisk (*). RA, right atrium; RPA, right pulmonary artery; RV, right ventricle; SVC, superior vena cava

\section{Case 2: Juxtaposed LAA}

A 2-year-old boy came to our institute with features of congestive heart failure. On examination, his heart rate was 110/minute and blood pressure was $90 / 50 \mathrm{~mm} \mathrm{Hg}$. A pan-systolic murmur was heard on the mitral area of chest. Transthoracic echocardiography (TTE) revealed situs solitus, levocardia, normally related great vessels, and a 7-mm muscular VSD. He was electively planned for surgical VSD closure. Transesophageal echocardiography performed after induction of anesthesia confirmed the findings of TTE. In addition, in the midesophageal five-chamber view, a slender, finger-like structure was visualized to the right side of the left atrium and the aortic valve (Fig. 5). Its narrow origin, continuity with the left atrium, location to the right of the aorta and pulmonary artery, and morphological resemblance to the LAA suggested the diagnosis of juxtaposed LAA. The juxtaposition of LAA was confirmed by the surgeon after opening the pericardium (Fig. 6). The LAA was found lying to the left of the aorta and cephalad to the right atrial appendage.

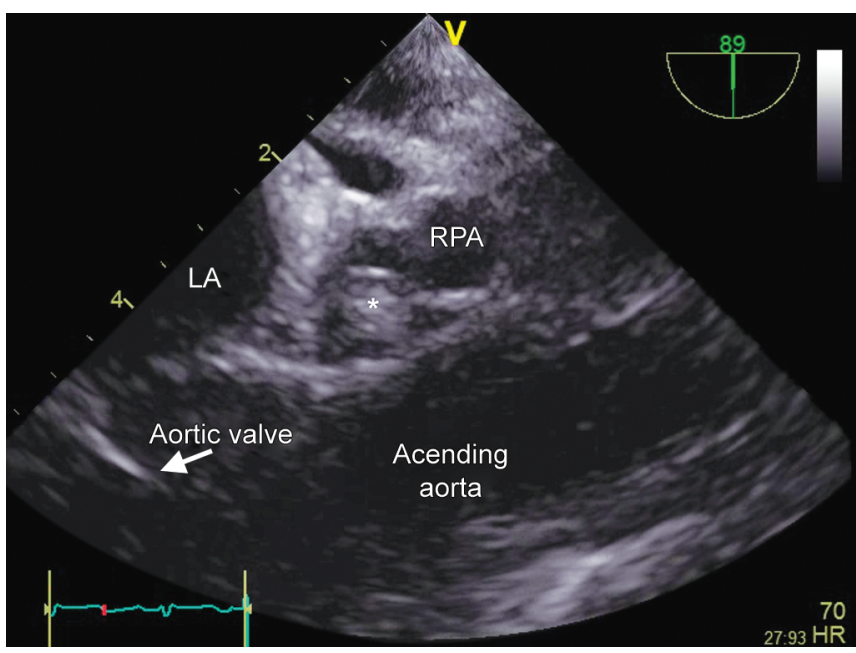

Fig. 3: Midesophageal ascending aorta long axis view in the first index case demonstrating the left atrial appendage $\left(^{*}\right)$, cephalad to the left atrium and caudal to the right pulmonary artery. LA, left atrium; RPA, right pulmonary artery

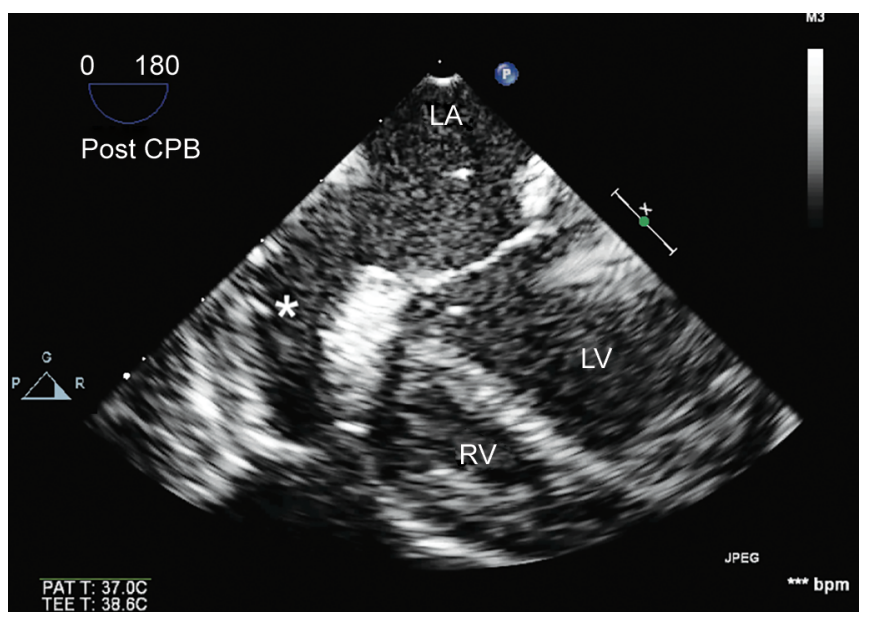

Fig. 5: Midesophageal view at the level of the left ventricle outflow tract in the second index case demonstrating the left atrial appendage ${ }^{*}$ ) lying to the right of the left atrium. LA, left atrium; LV, left ventricle; $\mathrm{RV}$, right ventricle

\section{Discussion}

The LAA is embryologically derived from the primitive atrium. ${ }^{4}$ Morphologically, it can vary in size, shape, and number of lobes and is commonly classified into the following four types: "chicken wing," "cauliflower," "cactus," and "windsock", based on its external appearance. ${ }^{4}$ Further variations may exist based on the location of the tip of the LAA. For example, a recent computed tomographic study on 320 consecutive patients by Koplay et al. has revealed 7 types of LAA morphology. ${ }^{2}$ Commonly, the LAA that arises from the left atrium is directed inferiorly, parallel to the pulmonary artery and extends between the anterior and lateral walls of the left atrium. In this location, because of its presence adjacent to the anterior wall of the left atrium, the LAA is visualized by TEE in the midesophageal two-chamber view. ${ }^{1}$ To enable a complete visualization of the LAA, it is recommended to obtain multiple views, including anteflexion from the midesophageal aortic valve short axis view and performance of a $0-180^{\circ}$ rotation of the omniplane angle. ${ }^{5}$ 


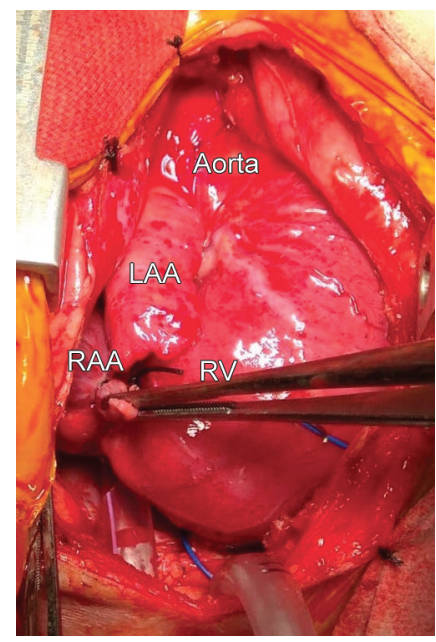

Fig. 6: Intraoperative photograph of the heart in the second index case demonstrating the juxtaposed LAA. LAA, left atrial appendage; RAA, right atrial appendage; $\mathrm{RV}$, right ventricle

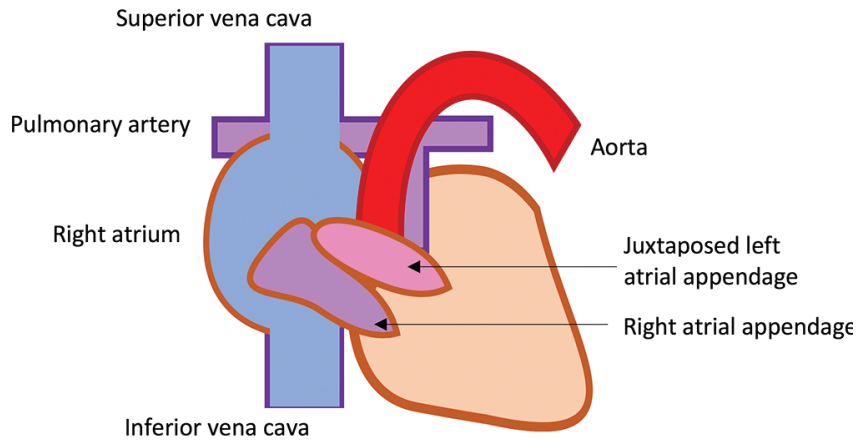

Fig. 8: Schematic representation of juxtaposed left atrial appendage, which was present in our second index case, as visualized after sternotomy

Juxtaposition of the atrial appendages refers to the condition in which both atrial appendages or one and part of the other lie beside each other and to one side of the great arterial vessels. ${ }^{6}$ Juxtaposition of appendages has been classified in two ways: Dixon classification and Van Praagh classification. ${ }^{7,8}$ Right juxtaposed atrial appendage implies that both the appendages are situated to the right side of the great arterial vessels. Juxtaposed LAA implies that it is the LAA which is abnormally positioned and hence juxtaposed.

In our first index case, the LAA was located posterior to the ascending aorta, superior to the left atrium, and inferior to the right pulmonary artery (Fig. 7). Among the types of LAA morphology described in the study by Koplay et al., one of the types, type III, refers to the appendage tip initially being oriented superiorly and later turning medially to lie between the pulmonary artery and left atrial body. ${ }^{2}$ At the outset, it may appear that the LAA in our first index case was similar to type III. However, the LAA tip in our case was lying more medially and extending posterior to the aorta, unlike what has been described by Koplay et al. Anecdotal evidence cites

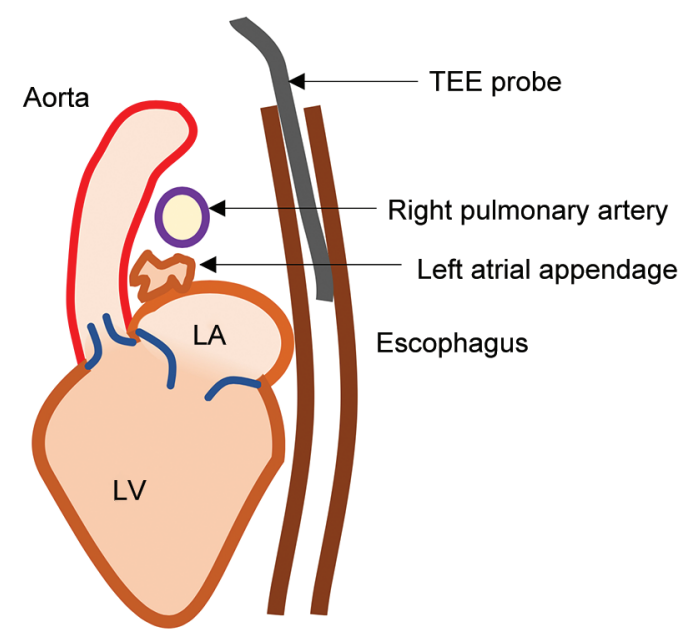

Fig. 7: Schematic representation of the location of the left atrial appendage posterior to the ascending aorta and caudal to the right pulmonary artery, in the sagittal view, as was seen in our first index case

the rare occurrence of location of LAA tip behind the arterial pedicle in the transverse sinus, but data on the incidence of such a finding are lacking. ${ }^{1}$ In the first index case, we could not completely rule out, based on the available literature, that this was a variant of right juxtaposition of atrial appendages, given the presence of cardiac anomalies in this case. Van Praagh et al., in their series of juxtaposed LAA in postmortem hearts, have described a similar case, but have refrained from naming it as juxtaposed LAA. ${ }^{8}$

In our second index case, both the left and right atrial appendages were lying to the right side of the aorta and pulmonary artery (Fig. 8). This was unlike the first index case, where the LAA was hardly in apposition to the right atrial appendage. Based on the classification chosen, our second index case can be alternatively named as right juxtaposed atrial appendages or juxtaposed LAA. The absence of heterotaxy syndromes enables us to name the feature in both ways. Van Praagh et al. have described partial juxtaposed LAA as the presence of pectinate muscles in the wall of the left atrium away from the LAA. ${ }^{8}$ In our second index case, while the LAA could be visualized on the surgical field, the left atrium was not surgically examined and hence, we are unable to comment on the diagnosis of complete or partial juxtaposed LAA.

The incidence of juxtaposed atrial appendages has been reported to be $0.28-1.1 \%$, and left-sided juxtaposition has been reported to be six times more common than right-sided juxtaposition which was diagnosed in our second index case. ${ }^{6,7}$ The abnormal orientation of the interatrial septum often provides clues to the diagnosis on TTE. ${ }^{7}$ Nevertheless, transesophageal examination in the operating room can clinch the diagnosis when the preoperative images are not available, as was true in our case. Also, in both our cases, the LAA could not be visualized by TEE in their usual position. Juxtaposed LAA is often associated with normal conus and can be coexisting with defects including atrial septal defects (ASD), VSD, mitral stenosis or atresia, hypoplastic left ventricle, and aortic outflow obstruction. ${ }^{8}$ In cardiac surgery, inversion of a juxtaposed LAA to fashion a patch for ASD closure has been described. ${ }^{9}$ The abnormally positioned appendage may also be mistaken for other structures or thrombi and confound proper anatomical diagnosis. In our first index, while there was an initial suspicion of thrombus in the pulmonary artery, this was 
quickly clarified on further examination. In the second index case, TEE aided in confirming the communication of the structure with the left atrium and simply hastened the diagnosis. Hence, these cases illustrate the importance of awareness of juxtaposed atrial appendages for the perioperative echocardiographer.

\section{References}

1. Beigel R, Wunderlich NC, Ho SY, et al. The left atrial appendage: anatomy, function, and noninvasive evaluation. JACC CardiovasC Imaging 2014;7(12):1251-1265. DOI: 10.1016/j.jcmg.2014.08.009.

2. Koplay M, Erol C, Paksoy Y, et al. An investigation of the anatomical variations of left atrial appendage by multidetector computed tomographic coronary angiography. Eur J Radiol 2012;81(7): 1575-1580. DOI: 10.1016/j.ejrad.2011.04.060.

3. Hahn RT, Abraham T, Adams MS, et al. Guidelines for performing a comprehensive transesophageal echocardiographic examination: recommendations from the American Society of Echocardiography and the Society of Cardiovascular Anesthesiologists. Anesth Analg 2014;118(1):21-68. DOI: 10.1213/ANE.0000000000000016.
4. Naksuk N, Padmanabhan D, Yogeswaran V, et al. Left atrial appendage: embryology, anatomy, physiology, arrhythmia and therapeutic intervention. JACC Clin Electrophysiol 2016;2(4):403-412. DOI: 10.1016/j.jacep.2016.06.006.

5. Bansal M, Kasliwal RR. Echocardiography for left atrial appendage structure and function. Indian Heart J 2012;64(5):469-475. DOI: 10.1016/j.ihj.2012.07.020.

6. Charuzi Y, Spanos PK, Amplatz K, et al. Juxtaposition of the atrial appendages [internet]. Circulation 1973;47(3):620-627. DOI: 10.1161/01.cir.47.3.620.

7. Singhi AK, Pradhan P, Agarwal R, et al. Juxtaposed atrial appendages: a curiosity with some clinical relevance. Ann Pediatr Cardiol 2016;9(2):186-189. DOI: 10.4103/0974-2069.173546.

8. Van Praagh S, O'Sullivan J, Brili S, et al. Juxtaposition of the morphologically left atrial appendage in solitus and inversus atria: a study of 18 postmortem cases [internet]. Am Heart J 1996; 132(2 Pt 1):391-402. Available from http://dx.doi.org/10.1016/s00028703(96)90438-X.

9. Andersen ND, Pal JD, Lodge AJ. Atrial septal defect repair by inversion of a juxtaposed left atrial appendage. Cardiol Young 2012;22(1): 103-105. DOI: 10.1017/S1047951111000801.

Video 1: Upper esophageal ascending aorta short axis view in the first index case demonstrating echogenic structure posterior to the ascending aorta

Video 2: Color Doppler in the upper esophageal ascending aorta short axis view in the first index case demonstrating the absence of flow around the echogenic structure

Video 3: Upper esophageal ascending aorta long axis in the first index case demonstrating echogenic structure cephalad to the left atrium and caudal to the right pulmonary artery

Video 4: Intraoperative video of the first index case revealing the left atrial appendage posterior to the aorta and caudal to the right pulmonary artery 